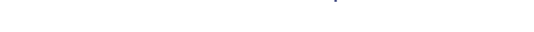

\title{
SARS-CoV-2: una revisión bibliográfica de los temas más relevantes y evolución del conocimiento médico sobre la enfermedad
}

\section{SARS-CoV-2: a bibliographic review of the most relevant topics and evolution of medical knowledge about the disease}

\author{
Ana Karina Vargas-Lara, ${ }^{*}$ Viviane Schreiber-Vellnagel, ${ }^{*}$ Eric Ochoa-Hein, ${ }^{* \neq}$ Alberto López-Ávila*, \\ *Universidad La Salle, Ciudad de México, México; \\ ${ }^{\ddagger}$ Instituto Nacional de Ciencias Médicas y Nutrición Salvador Zubirán, Ciudad de México, México; \\ §Universidad Autónoma Metropolitana, Ciudad de México, México.
}

\begin{abstract}
RESUMEN. Desde diciembre de 2019 el mundo se ha visto afectado por una pandemia causada por el virus SARS-CoV-2, el cual pertenece a la familia de los $\beta$-coronavirus, conocidos por su gran capacidad infecciosa, rápida transmisión y por manifestarse clínicamente como un síndrome respiratorio que ha provocado la muerte de más de 300,000 personas a nivel mundial. Este documento fue realizado de marzo a mayo de 2020 con el propósito de informar sobre los temas más relevantes de la enfermedad, antecedentes históricos, morfología viral, fisiopatología, transmisión, manifestaciones clínicas, características clínicas de los pacientes infectados y de los pacientes asintomáticos, período de incubación, pruebas diagnósticas, resultados esperados en las pruebas de laboratorio e imagen, principales complicaciones de la infección, posibles tratamientos, estatus del desarrollo de una vacuna y el uso de plasma convaleciente en el tratamiento, prevención y cuidados personales para evitar la infección y por último, posible reinfección. Además de comparar y verificar la información entre varios artículos sobre cada subtema para tener una perspectiva amplia y completa de los diferentes resultados, hallazgos y opiniones que se han generado hasta el momento sobre COVID-19.
\end{abstract}

Palabras clave: 2019-nCoV, coronavirus, COVID-19, revisión, SARS-CoV-2.

\section{Correspondencia:}

Dra. Ana Karina Vargas-Lara

Universidad La Salle, Ciudad de México.

Correo electrónico: ana.karina.vargas@hotmail.com

Trabajo recibido: 18-VI-2020; aceptado: 10-VII-2020.

Citar como: Vargas-Lara AK, Schreiber-Vellnagel V, Ochoa-Hein E, López-Ávila A. SARS-CoV-2: una revisión bibliográfica de los temas más relevantes y evolución del conocimiento médico sobre la enfermedad. Neumol Cir Torax. 2020;79(3):185-196. https://dx.doi.org/10.35366/96655
ABSTRACT. Since December 2019 the world has been affected by a pandemic caused by the SARS-CoV-2 virus, which belongs to the $\beta$-coronavirus family. This group of viruses are known for their great infectious capacity, rapid transmission and clinical manifestation as a respiratory syndrome, which has caused the death of more than 300,000 people worldwide. This document was written from March to May 2020 in order to report of the most relevant issues of the disease; historical background, viral morphology, pathophysiology, transmission, clinical manifestations, clinical characteristics of infected patients and asymptomatic patients, incubation period, diagnostic tests, expected results in laboratory and imaging tests, main complications of infection, status of vaccine development and the use of convalescent plasma in treatment, development of a vaccine, prevention and personal care to avoid infection and, at last, possible reinfection. In addition, this article compares and verifies the information between various articles on each subtopic, to have a broad and complete perspective of the different results, findings and opinions about COVID-19.

Keywords: 2019-nCoV, coronavirus, COVID-19, review, SARS-CoV-2.

\section{INTRODUCCIÓN}

En diciembre de 2019 se identificaron varios casos de neumonía viral causados por un $\beta$-coronavirus en personas expuestas a un mercado mayorista de mariscos y animales húmedos en Wuhan, Hubei, China. Los coronavirus son virus envueltos de ARN de sentido positivo, pertenecen a la familia Coronaviridae y al orden Nidovirales. Las principales diferencias dentro de la familia se encuentran en el número, tipo y tamaño de las proteínas estructurales, las cuales producen alteraciones significativas en la estructura y morfología del virus. ${ }^{1,2}$ Se conocen seis especies que provocan enfermedades en el humano, de éstas, cuatro son prevalentes y causan síntomas típicos de resfriado (229E, OC43, NL63, HKU1). Las otras dos 
especies, síndrome respiratorio agudo severo (SARS-CoV) y síndrome respiratorio del Medio Oriente (MERS-CoV) son $\beta$-coronavirus causantes de entre 15 y 30\% de las infecciones del tracto respiratorio inferior cada año, ya que afectan el epitelio pulmonar provocando un síndrome respiratorio, que se caracteriza por presentar síntomas como neumonía, fiebre y dificultad para respirar. ${ }^{3}$ En recién nacidos, ancianos y personas con enfermedades subyacentes causa una enfermedad más grave que puede ser mortal.1,2,4

En México el primer caso reportado fue un hombre de 35 años de edad con antecedentes de haber viajado a Italia, país que presentó altos niveles de contagio después de China. Fue atendido en el Instituto Nacional de Enfermedades Respiratorias en el Ciudad de México. ${ }^{5}$ Actualmente, según los datos del Gobierno de la Ciudad de México, hasta el 30 de mayo de 2020 se ha reportado un total de 7,573 casos sospechosos y 23,623 casos confirmados, la mayoría hombres de 31-50 años de edad. De igual manera, se reportó que 4,423 pacientes se encuentran hospitalizados y 1,055 intubados, lo cual representa $80 \%$ de la ocupación hospitalaria. Lamentablemente, la cifra total de personal que ha perdido la vida a causa de la enfermedad COVID-19 es de 9,415 hasta el momento. ${ }^{6}$

\section{Antecedentes históricos}

El 31 de diciembre de 2019 se reportaron a la Organización Mundial de la Salud (OMS) varios casos de neumonía de causa desconocida asociados a un mercado de mariscos en Wuhan, China.? Después de realizar la secuenciación de ácidos nucleicos mediante el uso de PCR de transcripción reversa en tiempo real en células epiteliales del tracto respiratorio inferior de cuatro pacientes diagnosticados con neumonía de causa desconocida en el Hospital de Beijing, se descubrió un nuevo $\beta$-coronavirus llamado 2019-nCoV que después se nombró SARS-CoV-2. Este nuevo virus demostró tener información del subgénero Sarbecovirus, familia Orthocoronavirinae, lo que lo hace diferente de SARS-CoV y MERS-CoV. ${ }^{4}$ Un reporte publicado por Zhu et al. identificó el genoma del SARS-CoV-2, el cual muestra ser entre 75 y $80 \%$ idéntico al SARS-CoV. ${ }^{4}$ Se propaga en las mismas células en las que crece SARS-CoV y MERS-CoV; sin embargo, se identificó que crece mejor en el epitelio de la vía aérea humana a diferencia de los previamente mencionados. ${ }^{6}$

\section{Morfología viral}

Este nuevo virus, con un diámetro de 60 a 140 nm, de forma esférica, picos de aproximadamente 9 a $12 \mathrm{~nm}$ en la membrana del virus que le confieren la característica más destacada de los coronavirus y que han generado el nombre de este grupo, de apariencia de corona solar y viriones esféricos de $125 \mathrm{~nm}$ de diámetro. ${ }^{2,4,8}$ Como el resto de los coronavirus, SARS-CoV-2 contiene cuatro proteínas estructurales principales, las cuales son: las proteínas espiga (S), membrana (M), envoltura (E) y nucleocápside (N). ${ }^{2}$

La proteína $S$ es una glucoproteína que media la unión al receptor del huésped. ${ }^{2}$ La proteína $M$ es la proteína estructural más abundante, tiene tres dominios transmembranales y se cree que le da forma al virión. Estudios recientes refieren que las proteínas $M$ pueden adoptar dos conformaciones diferentes, lo que les permite unirse a la nucleocápside. ${ }^{2}$ La proteína $E$, de igual manera, una proteína transmembrana, se encuentra en pequeñas cantidades dentro del virión. Tiene actividad de canal iónico que facilita el ensamblaje y la liberación del virus, lo cual es importante para la patogénesis de la enfermedad. ${ }^{2}$ Por último, la proteína $\mathrm{N}$ es la única proteína presente en la nucleocápside, se compone de dos dominios separados, ambos capaces de unirse al ARN in vitro; sin embargo, cada dominio utiliza diferentes mecanismos para unirse al ARN. Se cree que para la adecuada unión se requiere la contribución de ambos dominios y se ha sugerido que la fosforilación de la proteína $\mathrm{N}$ desencadena un cambio estructural que mejora la afinidad por el ARN viral en vez del ARN no viral. A su vez, se piensa que la proteína N, en conjunto con la proteína $M$, interacciona para empaquetar el genoma encapsulado en partículas virales. ${ }^{2}$

Una quinta proteína estructural, la hemaglutinina-esterasa, presente en un subconjunto de $\beta$-coronavirus, permite la unión de las glucoproteínas de superficie. Se piensa que mejora la entrada hacia las células mediadas por la proteína $S$, y la propagación del virus a través de la mucosa. ${ }^{2}$

\section{Fisiopatología}

\section{Fusión con la membrana y entrada}

Como sucede en general con los coronavirus, la infección viral inicia con la unión del virión a la célula huésped mediante la interacción de la proteína $S$ y su receptor.

Se conoce que SARS-CoV, HCoV-NL63 y posiblemente SARS-CoV-2 utilizan la enzima convertidora de angiotensina 2 (ECA II) como su receptor, mientras que MERS-CoV se une al dipeptidil-peptidasa 4 (DPP4) para ingresar a las células humanas. ${ }^{2}$

Después de la unión al receptor, el virus tiene acceso al citosol de la célula huésped, una proteasa que permite la fusión de la membrana viral y celular. Una serie de divisiones en la proteína S permite la formación y liberación del genoma viral al citoplasma. ${ }^{2}$

\section{Proteínas de replicación}

El siguiente paso después de infectar las células del huésped es la replicación de las proteínas virales, el cual comienza 
con la traducción del ARN genómico del virión. Este gen codifica dos poliproteínas utilizando una secuencia ya descrita, 5'-UUUAAAC-3', que permite el desplazamiento del ribosoma en el marco de lectura. Se desconoce por qué los coronavirus utilizan el desplazamiento de marcos para controlar la expresión de proteínas, pero se cree que puede controlar la producción de poliproteínas o retrasar este proceso hasta que haya un entorno adecuado para la replicación del ARN. ${ }^{2}$

Los coronavirus codifican dos o tres proteasas tipo papaína (PLpro), las cuales se ensamblan en el complejo replicasa-transcriptasa (RTC) para crear un entorno adecuado para la síntesis de ARN. Además de las funciones de replicación, se ha identificado que bloquean la respuesta inmunitaria innata. La mayoría de los coronavirus codifican dos PLpros, excepto los $\gamma$-coronavirus, SARS-CoV y MERSCoV, que sólo expresan un solo PLpro. ${ }^{2}$

\section{Replicación y transcripción}

La etapa de replicación más importante es cuando se fusionan los segmentos de secuencias reguladoras transcripcionales (SRT) durante la producción de ARN subgenómico. Actualmente, se ha descrito que la ARN-polimerasa continúa el alargamiento del siguiente SRT o cambia para amplificar la secuencia líder en el extremo $5^{\prime}$ del genoma guiado por el SRT líder. En la actualidad, muchas pruebas respaldan este modelo, incluida la presencia de una secuencia antilíder en el extremo 3' de los ARN subgenómicos de cadena negativa. ${ }^{2}$ Por último, los coronavirus son conocidos por su capacidad de recombinarse; esta capacidad está ligada al cambio de cadena de la ARN-polimerasa. La recombinación tiene un papel destacado en la evolución viral y la patogenicidad de la infección. ${ }^{2}$

\section{Ensamblaje y liberación}

Después de la replicación y la síntesis de ARN subgenómico, las proteínas estructurales virales S, E y M se traducen y se insertan en el retículo endoplásmico de las células del huésped. Estas proteínas se desplazan al aparato de Golgi, donde se envuelven en la membrana y forman viriones maduros. ${ }^{2}$ La proteína M y E median la mayoría de las interacciones necesarias para el ensamblaje del coronavirus. Se cree que estas dos proteínas funcionan juntas para producir la envoltura viral y la incorporación de los viriones. ${ }^{2}$ Se desconoce cómo la proteína E ayuda a la proteína $\mathrm{M}$ en el ensamblaje del virión, y se han sugerido varias posibilidades: se dice que la proteína $\mathrm{E}$ actúa en la inducción de la curvatura de la membrana que previene la agregación de la proteína $M$; y por otra parte, tiene un papel separado en la liberación viral al alterar la vía secretora del huésped. ${ }^{2}$

Después del ensamblaje, los viriones son transportados a la superficie celular en vesículas y liberados por exocitosis.
No se sabe si los viriones usan la ruta tradicional desde el aparato de Golgi o si el virus ha desviado una ruta separada y única para su propia salida. Se ha descrito en varios coronavirus que la proteína $S$ no se ensambla en los viriones, transita a la superficie celular donde media la fusión entre las células infectadas y las células adyacentes no infectadas. Esto conduce a la formación de células gigantes multinucleadas, lo que permite que el virus se propague dentro de un organismo infectado sin ser detectado o neutralizado por anticuerpos específicos del virus. ${ }^{2}$

Por otro lado, la fisiopatología de la infección por SARS-CoV o MERS-CoV no se conoce completamente, a diferencia de los demás coronavirus, de los cuales se ha descrito el modo de infección como se menciona en párrafos anteriores. Sin embargo, se ha descrito que SARSCoV-2 utiliza el mismo receptor de entrada celular que el SARS-CoV. Infecta principalmente las células epiteliales del tracto respiratorio inferior, mediante el receptor de la enzima convertidora de angiotensina II (ECA II). Este mecanismo se lleva a cabo a través del virión S-glucoproteína en la superficie del coronavirus, que puede unirse al receptor ECA II en la superficie de las células humanas. Además, tiene la capacidad de ingresar en los macrófagos y células dendríticas, provocando la liberación de citocinas proinflamatorias que contribuyen a la enfermedad., ${ }^{9,10}$

\section{Respuesta del huésped a la infección}

Diversos artículos han reportado el aumento de citocinas proinflamatorias y respuesta reducida de células $T$ en la gravedad de la enfermedad, tanto en modelos roedores infectados con cepas de SARS-CoV como en pacientes positivos a COVID-19.1,2,1 Fher y colaboradores mencionan que los títulos virales parecen disminuir cuando se desarrolla una enfermedad grave tanto en humanos como en varios modelos animales de la enfermedad. ${ }^{2}$

Los primeros estudios reportaron aumento en suero de las siguientes citocinas proinflamatorias: IL1B, IL6, IL12, IFN $\gamma$, IP10 y MCP1, las cuales se asocian con la inflamación y daño pulmonar extenso en pacientes infectados por SARS-CoV, MERSCoV y actualmente SARS-CoV-2.,2,9 Por lo que se piensa que las altas cantidades de citocinas proinflamatorias producidas por la respuesta celular producen la activación de linfocitos Th1. Sin embargo, ahora es de nuestro conocimiento que la infección por SARS-CoV-2 también estimula la secreción de linfocitos Th2, principalmente IL4 e IL10, que suprimen la inflamación, a diferencia de la infección por SARS-CoV. Aunque se necesitan más estudios para confirmar esto. ${ }^{1}$

\section{Transmisión}

Con los primeros reportes de infección por SARS-CoV-2 fue posible identificar que la infección es transmitida de 
una persona a otra a través del contacto cercano y tanto la población inmunocompetente como inmunocomprometida son susceptibles. ${ }^{3}$ Las tres principales rutas de transmisión descritas fueron:

1. Transmisión por gotas: ocurre cuando una persona infectada tose o estornuda y las gotas liberadas son ingeridas o inhaladas por personas cercanas.

2. Transmisión por contacto: cuando un sujeto tiene contacto con superficies u objetos contaminados con el virus y posteriormente se toca la boca, la nariz o los ojos.

3. Transmisión por aerosoles: sucede cuando las gotas respiratorias se mezclan en el aire del ambiente de un lugar relativamente cerrado, formando aerosoles que se inhalan en altas dosis causando infección.

Después de varias hipótesis, ahora se sabe que la principal vía de transmisión de SARS-CoV-2 es de una persona a otra entre miembros de la familia, incluidos familiares y amigos que han estado en contacto íntimo con pacientes o portadores de incubación, a diferencia del SARS-CoV y MERS-CoV, cuya vía principal de transmisión es la nosocomial. ${ }^{10}$ Además, las personas que se encuentran en período de incubación se consideran posibles transmisores. ${ }^{9}$

Gracias a estudios recientes en pacientes positivos a COVID-19 que presentaban molestias abdominales y síntomas de diarrea, ahora sabemos que en menor frecuencia la transmisión fecal es posible. Se ha demostrado que en el sistema digestivo los enterocitos del íleon y el colon expresan altamente receptor de ECA II.,8,8 Por lo que se ha detectado la presencia de SARS-CoV-2 en muestras fecales, hisopos fecales y sangre en pacientes con neumonía grave. ${ }^{10}$ Se observó que las partículas del virus se detectan de dos a cinco días previo a la aparición de los síntomas respiratorios y después de tratamiento con corticosteroides, lo cual sugiere que las partículas del virus sobreviven por más tiempo en el tracto gastrointestinal en comparación con el tracto respiratorio. ${ }^{12}$

Cabe mencionar que en el artículo Aerosol y estabilidad de la superficie del SARS-CoV-2 en comparación con SARSCoV-1 se reportó que SARS-CoV-2 es capaz de permanecer hasta 6.8 horas en plásticos, 5.6 horas en acero inoxidable y aproximadamente entre 1.1-1.2 horas en cobre. Después de este tiempo el virus demostró disminución exponencial en el título del virus en todas las condiciones experimentales. ${ }^{13}$

\section{Manifestaciones clínicas}

De los primeros casos confirmados de infección por SARSCoV-2 para el 2 de enero de 2020, los síntomas más comunes al inicio de la enfermedad fueron: fiebre en 40 de 41 pacientes (98\%), tos en 18 pacientes $(44 \%)$ y 22 pacientes desarrollaron disnea (55\%). De los síntomas menos comunes fueron: producción de esputo en 11 de 39 pacientes (28\%), cefalea en tres de $38(8 \%)$, hemoptisis en dos de $39(5 \%)$ y únicamente un paciente de 38 presentó diarrea (3\%). La mediana de duración desde el inicio de la enfermedad hasta la disnea fue de ocho días, el desarrollo del síndrome de dificultad respiratoria aguda (SDRA) fue de nueve días y hasta la ventilación mecánica fue de 10.5 días; al igual que el ingreso a unidad de cuidados intensivos (UCI) debido al daño alveolar que en pacientes de mediana edad y ancianos con enfermedades preexistentes (cirugía tumoral, cirrosis, hipertensión arterial, enfermedad coronaria, diabetes y enfermedad de Parkinson) produjo la muerte. De igual manera se reporta que los pacientes con síntomas leves se recuperaron después de una semana (Figura 1)1,1,3

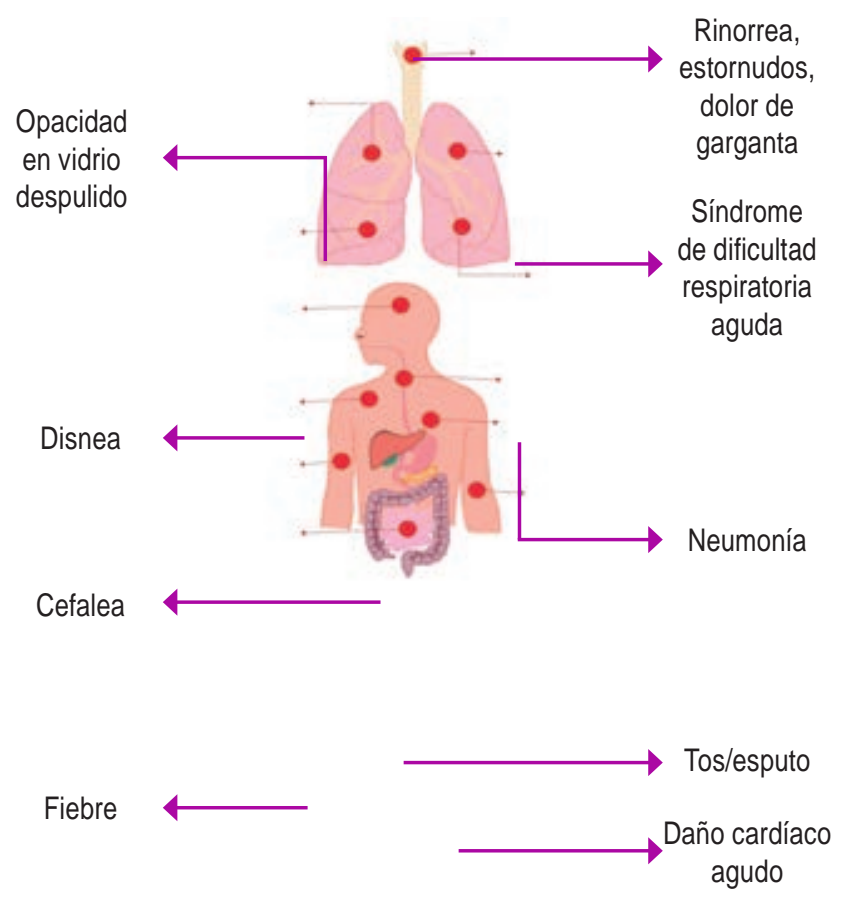

Linfopenia
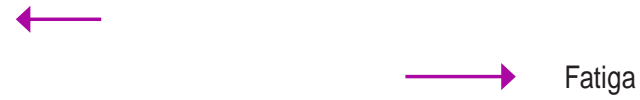

Diarrea

Figura 1: Principales manifestaciones respiratorias y sistémicas de la infección por SARS-CoV-2. Los principales síntomas que se presentan cuando se afecta el tracto respiratorio superior son: rinorrea, estornudos, dolor de garganta. Mientras que las manifestaciones del tracto respiratorio inferior son: neumonía, opacidades en vidrio despulido y síndrome de dificultad respiratoria aguda. Por otro lado, los síntomas más frecuentes de afección sistémica son: fiebre, tos, fatiga, esputo productivo, cefalea, disnea y linfopenia. En menor frecuencia: hemoptisis, daño cardíaco agudo y diarrea. Modificado de: Okhuese AV. ${ }^{14}$ 
Actualmente sabemos que los síntomas gastrointestinales, menos alarmantes que los síntomas y complicaciones respiratorias, se van presentado conforme avanza la historia natural de la enfermedad por COVID-19. Se ha reportado que $79 \%$ de los pacientes presentan síntomas como diarrea, náusea, vómito, disminución del apetito, dolor abdominal y sangrado gastrointestinal durante su hospitalización. En adultos el síntoma más frecuente fue anorexia, mientras que el vómito se reportó más en los pacientes pediátricos. ${ }^{12}$

Además, se han agregado dos síntomas que pueden ser sugestivos de infección por SARS-CoV-2, ya que se presentan en la etapa inicial de la enfermedad, los cuales son: anosmia, pérdida del olfato, o ageusia, pérdida del gusto. Lee et al. reportaron que de 3,191 pacientes interrogados, $15.3 \%$ presentaron anosmia o ageusia, $20.3 \%$ sólo presentó ageusia y $27.7 \%$ sólo anosmia. De éstos, $62.7 \%$ fueron mujeres jóvenes de 25 a 59 años de edad. De igual manera, menciona que la mayoría de los pacientes con anosmia o ageusia se recuperaron dentro de tres semanas, mientras que en los pacientes de edad temprana, entre 20 y 39 años persistió la anosmia. ${ }^{15}$ Hasta el momento se cree que la causa de la anosmia se debe al daño en el nervio olfatorio durante la invasión y multiplicación de SARS-CoV-2 en el organismo del huésped, en tanto que la ageusia puede ser resultado secundario de la disfunción olfatoria. ${ }^{12}$ Cabe mencionar que el principal receptor de SARS-CoV-2, ECA II, se expresa ampliamente en las células epiteliales de la mucosa oral, lo que podría explicar el mecanismo patogénico de esta pérdida en los sentidos del olfato y el gusto. ${ }^{15}$

Por otra parte, se han reportado alteraciones cutáneas en los pacientes positivos a COVID-19, Pérez-Suárez et al. reportaron que de 86 casos valorados con una media de edad de 29 años y 56\% mujeres, la reacción cutánea más frecuente es la urticaria en $25 \%$, seguida de exantemas en $19 \%$ y pseudoperniosis en $12 \%$. Otro de los hallazgos fue la acrocianosis, signo que refleja la hipoxia periférica, posiblemente relacionada con los fenómenos trombóticos tanto a nivel cutáneo como en los vasos de otros órganos. Este signo se observó principalmente en pacientes que requirieron ingreso hospitalario. ${ }^{16}$

De igual manera los pacientes en edad pediátrica presentan los mismos síntomas (fiebre, fatiga y tos). Sin embargo, suele presentarse fiebre baja o moderada y la enfermedad suele progresar en uno a tres días a falla respiratoria de difícil control con oxígeno. Después de una semana de infección puede presentarse cianosis y disnea, acompañadas de falta de apetito y disminución de la actividad así como cansancio. Por otro lado, en los casos más severos puede presentarse choque séptico, acidosis metabólica, hemorragias no reversibles y coagulopatías. ${ }^{9}$

\section{Características clínicas de los pacientes infectados}

Las características más destacadas que se han reportado entre los pacientes infectados por SARS-CoV-2: son pacientes entre 25 y 59 años de edad, con una mediana de edad de 49 años. La mayoría de los infectados son hombres en $59 \%$, con enfermedades subyacentes; de éstas, las más comunes son: diabetes mellitus tipo 2, hipertensión arterial sistémica y enfermedades cardiovasculares no especificadas. ${ }^{1,3,10}$ Además, se ha identificado que la población de mayor riesgo son personas con función inmunitaria deficiente, principalmente personas con disfunción renal y/o hepática, personas mayores de 60 años con disfunción renal y/o hepática y mujeres embarazadas. ${ }^{3}$

Cabe mencionar que a pesar de que los hombres han demostrado mayor predisposición a la infección, las mujeres presentan mayor sintomatología y manifestaciones clínicas variables por un mayor período de tiempo.

\section{Características clínicas de los pacientes asintomáticos}

De los pacientes asintomáticos se conoce, según lo que reporta Bao, que la mayoría son jóvenes entre 27 y 56 años y en su mayoría hombres. De 11 pacientes estudiados, ninguno presentaba síntomas de la enfermedad COVID-19; sin embargo, el resultado de la prueba fue positivo. En todos ellos se realizaron estudios de imagen, donde se encontró que seis pacientes presentaban hallazgos anormales en la TAC de tórax, principalmente opacidades en vidrio esmerilado. Las células sanguíneas de todos, función hepática, función renal, función de la coagulación y proteína C reactiva de alta sensibilidad estaban en rango normal. Además, ninguno desarrolló neumonía severa, únicamente síntomas leves en comparación con los reportados en Wuhan. ${ }^{17}$

\section{Período de incubación}

Se ha reportado que los síntomas de infección por SARSCoV-2 aparecen después de un período de incubación de uno a 14 días, con mayor frecuencia de tres a siete días, con una media de 5.2 días. ${ }^{10,18}$ Se conoce que este período depende de la edad y del estado del sistema inmunitario del paciente. Se han reportado períodos más cortos en pacientes mayores de 70 años. Ahora es de nuestro conocimiento que el período desde el inicio de los síntomas hasta la muerte oscila entre seis y 41 días con una mediana de 14 días (Figura 2). ${ }^{18}$

\section{Pruebas diagnósticas sugestivas de infección}

En los casos de infección autolimitada el diagnóstico de coronavirus es innecesario, ya que la enfermedad naturalmente seguirá su curso. ${ }^{9}$ Sin embargo, puede ser importante 


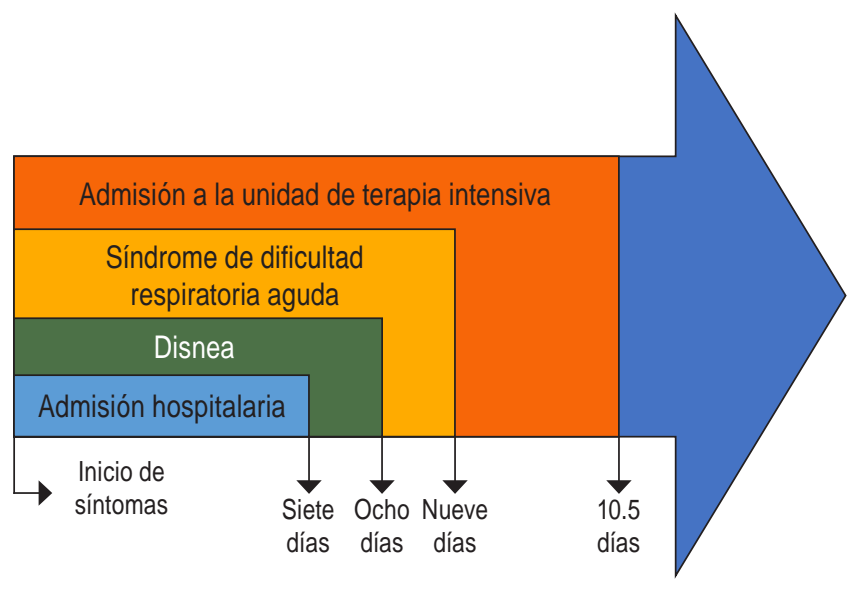

Tiempo promedio

Figura 2: Tiempo promedio en días desde la admisión hospitalaria hasta el ingreso a la unidad de terapia intensiva en la infección por SARS-CoV-2. Desde el inicio de los síntomas hasta la admisión hospitalaria trascurre un tiempo promedio de siete días. Posteriormente, con el paso de 24 horas entre cada manifestación clínica, se comienza a presentar disnea, síndrome de dificultad respiratoria aguda y en un promedio de 10.5 días, la admisión a la unidad de terapia intensiva. Modificado de: Huang $\mathrm{C}$ et al.

en estudios epidemiológicos identificar un agente etiológico o lugares donde se está produciendo un brote grave de SARS-CoV-2, con el objetivo de desarrollar medidas de salud pública y el control de brotes. El estudio por RT-PCR se ha convertido en el método de elección para el diagnóstico de COVID-19, ya que detecta el ácido nucleico de SARS-CoV-2 en muestras de esputo, hisopos de garganta y secreciones del tracto respiratorio inferior. ${ }^{3,9}$ Los ensayos serológicos son importantes en los casos en que el ARN sea difícil de aislar o ya no está presente, y para estudios epidemiológicos. ${ }^{9}$

\section{Resultados en pruebas de laboratorio}

Hoy en día es de nuestro conocimiento que los pacientes positivos a COVID-19 presentan alteración en el recuento sanguíneo, principalmente leucopenia, leucocitosis y linfopenia, siendo este último el hallazgo más común. ${ }^{1,19,20}$ Además, se ha identificado que altos niveles de dímero $\mathrm{D}$ mayores de $2,400 \mathrm{ng} / \mathrm{mL}$ se deben considerar al ingreso hospitalario aún en ausencia de síntomas severos, ya que esta elevación representa un incremento en la generación de trombina, siendo el parámetro de laboratorio más apropiado para reconocer el estado trombofílico y poder comenzar terapia antitrombótica de forma oportuna. ${ }^{11,19}$ Cabe mencionar que se han asociado altos niveles de dímero $\mathrm{D}$ y linfopenia severa a altas posibilidades de mortalidad. ${ }^{19}$

Asimismo, se ha identificado que la hiperferritinemia, ferritina mayor de $500 \mathrm{ng} / \mathrm{mL}$ es el mejor indicador de la presencia de la respuesta inmunitaria exagerada debido al síndrome de activación macrofágica (SAM). ${ }^{11}$ Por lo que se recomienda que a los pacientes que acudan por COVID-19 se les realicen las siguientes pruebas: dímero D, tiempo de protrombina (TP), tiempo parcial de tromboplastina (TPT), fibrinógeno y recuento diferencial de glóbulos blancos. ${ }^{20}$

\section{Resultados en pruebas de imagen}

Los resultados y hallazgos que con mayor frecuencia se han reportado en pruebas de imagen de pacientes infectados por SARS-CoV-2 son anormalidades en las imágenes por tomografía computarizada (TC) de tórax, principalmente múltiples opacidades de vidrio esmerilado periférico en regiones subpleurales de ambos pulmones con distribución periférica, involucro de los lóbulos inferiores y conforme progresan las opacidades pulmonares el cuadro clínico de estos pacientes empeora. ${ }^{1,3,18,19}$ Además, en las radiografías de tórax al ingreso hospitalario de pacientes con COVID-19 se han observado infiltrados en los lóbulos superiores de los pulmones, lo cual se asocia al aumento de la disnea con hipoxemia. ${ }^{18}$ Asimismo, se ha identificado que durante el período de hospitalización los pacientes presentan nuevos infiltrados pulmonares en las radiografías de tórax. ${ }^{3}$ Dentro de los hallazgos menos frecuentes se reporta engrosamiento pleural, derrame pleural y linfadenopatía. ${ }^{19}$

\section{Principales complicaciones de la infección por COVID-19}

Debido a que la mayoría de los pacientes desarrollan neumonía, la principal complicación que se presenta durante el desarrollo de la enfermedad por COVID-19 es SDRA, seguida de lesión cardíaca aguda. En menor frecuencia se puede presentar arritmia, shock, lesión renal aguda, disfunción hepática e infecciones secundarias. ${ }^{1,3,10}$ La mayoría de los pacientes requieren ventilación mecánica y/o presentan hipoxemia refractaria. ${ }^{1}$ Se ha identificado que las principales complicaciones que condujeron a la muerte fueron: SDRA, lesión cardíaca aguda y opacidades de gran tamaño en los pulmones. ${ }^{3}$

Guana y su grupo mencionan que los pacientes positivos a COVID-19 se agravan rápidamente debido al SAM, en el cual se observa proliferación incontrolada de células Ty activación excesiva de los macrófagos. También mencionan que además de la respuesta macrofágica descontrolada, los pacientes presentan una activación patológica de la trombina generando múltiples episodios trombóticos que se presentan desde isquemia periférica, tromboembolismo pulmonar y coagulación intravascular diseminada, que fueron las principales complicaciones por las que varios pacientes infectados por SARS-CoV-2 fallecieron. ${ }^{11}$ 


\section{Tratamiento y manejo hospitalario}

Hasta la fecha no existen terapias antivirales que se dirijan específicamente a COVID-19, por lo que los tratamientos son únicamente de apoyo. ${ }^{9}$ Se recomienda aplicar un tratamiento sintomático apropiado y atención de apoyo, además de prevenir infecciones nosocomiales y atender problemas de salud psicológica asociados tanto a casos confirmados, casos sospechosos y personal médico. ${ }^{3}$

Cabe mencionar que diversos artículos han reportado el uso de hidroxicloroquina/cloroquina solo o en combinación con azitromicina en el tratamiento de pacientes con COVID-19 confirmado con neumonía leve, específicamente en casos de pacientes con TAC positiva sin necesidad de oxígeno o infección no grave. Actualmente, se ha informado que la hidroxicloroquina/cloroquina no ha demostrado efectos beneficiosos en la progresión clínica en pacientes con COVID-19 o en el aclaramiento viral utilizando la prueba de reacción en cadena de la polimerasa (PCR) como método de medición. Algunos artículos mencionan una mejoría clínica; sin embargo, la evidencia se ha calificado como baja. ${ }^{21}$

De igual manera, el uso de hidroxicloroquina/cloroquina en combinación con azitromicina en pacientes hospitalizados por COVID-19 ha reportado falla en el aclaramiento viral y efectos adversos, principalmente prolongación significativa del intervalo QT que conduce a la interrupción del tratamiento. El riesgo reportado de mortalidad entre los pacientes que recibieron este tratamiento durante la estancia hospitalaria fue de $3.4 \%{ }^{21}$ Cabe resaltar que también se han publicado varios informes de casos que refieren prolongación del intervalo QT relacionados con el uso de hidroxicloroquina. Por otro lado, los pacientes que únicamente reciben azitromicina han presentado prolongación del intervalo QT, torsades de pointes, taquicardia ventricular $y$, en un estudio reciente, los pacientes que tomaron un ciclo de azitromicina de cinco días tuvieron mayor riesgo de muerte súbita cardíaca. ${ }^{21}$ Se recomienda que los pacientes con COVID-19 que reciban este tratamiento se monitoreen con electrocardiograma (ECG) de referencia y de seguimiento y que se vigile cuidadosamente el uso de otros medicamentos concomitantes conocidos por prolongar el intervalo QT. ${ }^{21}$

A su vez, se reporta que los inhibidores de la proteasa, lopinavir y ritonavir utilizados para tratar la infección por el virus de la inmunodeficiencia humana (VIH) podrían mejorar el resultado de los pacientes con MERS-CoV y SARS-CoV, ya que estos fármacos han demostrado disminuir significativamente la carga viral de $\beta$-coronavirus de un paciente con COVID-19 después del tratamiento con lopinavir/ritonavir. ${ }^{10}$ Se ha reportado que el uso de lopinavir/ritonavir no ha demostrado efectos beneficio- sos en la mortalidad. Además, se ha reportado que los pacientes positivos a COVID-19 que reciben este tratamiento no han podido completar el ciclo de 14 días, ya que los principales efectos adversos gastrointestinales son: anorexia, náuseas, molestias abdominales o diarrea así como episodios de gastritis aguda. ${ }^{21}$ Asimismo, se ha documentado que esta combinación de fármacos presenta alto riesgo de lesión hepática, pancreatitis, erupciones cutáneas graves, prolongación del intervalo QT y múltiples interacciones farmacológicas debido a la inhibición del CYP3A. ${ }^{21}$

Actualmente se está realizando un estudio controlado, adaptativo y aleatorizado en diferentes países a través de la OMS, el cual se encuentra en fase 2 de investigación, con el objetivo de comparar el uso de lopinavir durante 14 días, hidroxicloroquina por 10 días, remdesivir por nueve días y la atención de apoyo durante la estancia hospitalaria en pacientes con COVID-19. ${ }^{22}$ Otro estudio que se lleva a cabo en el Hospital Universitario de Oslo, el cual se encuentra en fase 3 de investigación, evalúa la seguridad y eficacia de la hidroxicloroquina, remdesivir y la atención estándar en pacientes adultos hospitalizados por COVID-19. ${ }^{23}$

Por otro lado, se ha discutido en diversos artículos el uso de corticoesteroides en pacientes hospitalizados por COVID-19 y en la actualidad los reportes continúan siendo variados. Los primeros artículos generados en China mencionan que el uso de este grupo de fármacos se utilizó para evitar el SDRA en pacientes con neumonía por COVID-19; sin embargo, reportes actuales han demostrado que los corticoesteroides tienen un efecto variable o nulo en pacientes críticos con insuficiencia pulmonar secundaria a la infección por SARS-CoV-2. Además, se ha mencionado que los corticoesteroides pueden provocar un retraso en la eliminación viral. ${ }^{21}$ Por el contrario, otros artículos mencionan que el uso de corticoesteroides de dosis bajas a moderadas en pacientes críticos por COVID-19 reduce la mortalidad, acorta la duración de la estancia hospitalaria y evita infecciones secundarias. ${ }^{24}$ Se necesita investigación e información más amplias, principalmente porque estos fármacos se han utilizado únicamente en pacientes críticos; y también para poder estandarizar una dosis, el momento indicado durante la historia natural de la enfermedad, la duración adecuada en la prevención del deterioro clínico y la verdadera eficacia de estos fármacos.

Actualmente en Francia se realiza un estudio en fase 2 de investigación con 304 participantes, el cual evalúa el uso de corticoesteroides, específicamente prednisona, para el control temprano de la respuesta inflamatoria exacerbada y así reducir el riesgo de desarrollar SDRA y la tasa de pacientes hospitalizados con neumonía viral por COVID-19 que necesitan suplemento de oxígeno de alto 
flujo o transferencia a la UCI para soporte respiratorio durante la fase aguda de la enfermedad, además de evaluar el beneficio, la seguridad y la tolerancia del tratamiento con corticoesteroides. ${ }^{25}$ Otros estudios realizados en Michigan, Estados Unidos y Hubei, China, con el mismo objetivo, reportan utilizar metilprednisolona, en lugar de prednisona, a una dosis de 0.5 a $1 \mathrm{mg} / \mathrm{kg}$ al día dividido en dos dosis por tres días y $1 \mathrm{mg} / \mathrm{kg}$ al día por siete días, respectivamente. Cabe mencionar que ambos estudios han completado la fase de investigación; sin embargo, aún no se han publicado los resultados. ${ }^{26,27}$

Otro fármaco utilizado en pacientes críticos por $\mathrm{CO}$ VID-19 es el tocilizumab, un inhibidor de IL-6, una de las citocinas proinflamatorias liberadas en respuesta a la infección por SARS-CoV-2, el cual ha demostrado reducir la mortalidad de este grupo de pacientes en un estudio sin grupo control, por lo que estos datos pueden ser inciertos. ${ }^{21}$ Por otro lado, se ha reportado mayor riesgo de infecciones graves (bacterianas, virales, infecciones fúngicas invasivas y tuberculosis), reactivación de la hepatitis $B$, anafilaxia, reacciones alérgicas graves, daño e insuficiencia hepática grave y perforación intestinal. ${ }^{21}$ El estudio e investigación de este fármaco aún es insuficiente para determinar la efectividad en pacientes críticos por COVID-19.

Un estudio reciente que se encuentra en fase 3 de investigación con 500 participantes, el cual utiliza ruxolitinib, otro fármaco inhibidor de IL-6, tiene el objetivo de evaluar la eficacia y seguridad de este medicamento en el tratamiento de pacientes con ventilación mecánica debido a COVID-19. ${ }^{28}$ Otro estudio, que también se encuentra en fase 3 de investigación, evalúa este medicamento en pacientes mayores de 12 años de edad con neumonía secundaria a la infección por SARS-CoV-2 durante 29 días en comparación con un placebo, de igual manera, con el objetivo de valorar la seguridad y eficacia del fármaco. ${ }^{29}$ A su vez, en México se está desarrollando un estudio que se encuentra en fase 2 de investigación, el cual pretende evaluar la capacidad del ruxolitinib para detener la respuesta inmunológica desregulada causada por COVID-19 y de esta manera, evitar la evolución a neumonía y SARS-CoV. ${ }^{30}$ Además, en Madrid, España se realiza un estudio utilizando ruxolitinib en combinación con simvastatina con la finalidad de lograr un efecto sinérgico en la inhibición de la entrada, efecto antiinflamatorio y potenciar la respuesta inmunológica adaptativa de los pacientes en etapas tempranas de la infección por SARS-CoV-2. ${ }^{31}$

Actualmente es de nuestro conocimiento que los pacientes positivos a COVID-19 deben recibir anticoagulación profiláctica estándar con heparina de bajo peso molecular (HBPM), enoxaparina $100 \mathrm{UI} / \mathrm{kg}$ vía subcutánea cada 24 horas hasta la recuperación del paciente, ya que aumenta la actividad de la antitrombina III bloqueando la activación patológica de la trombina, evitando los fenómenos trom-
Tabla 1: Estatus de los antivirales y otros fármacos utilizados en el tratamiento de pacientes positivos a SARS-CoV-2.

\begin{tabular}{|l|l|l|}
\hline \multicolumn{1}{|c|}{$\begin{array}{c}\text { Medicamentos } \\
\text { utilizados }\end{array}$} & $\begin{array}{c}\text { Medicamentos en } \\
\text { investigación }\end{array}$ & \multicolumn{1}{c|}{$\begin{array}{c}\text { Medicamentos } \\
\text { en fase III }\end{array}$} \\
\hline - Lopinavir/ritonavir & - Nafamostat & • Remdesivir \\
- Cloroquina & - Ganciclovir & (GS-5734) \\
- Ribavirina & - Favipiravir (T-705) & \\
- Oseltamivir & - Nitazoxanida & \\
- Penciclovir/aciclovir & & \\
- Ganciclovir & & \\
- Nitazoxanida & & \\
\hline
\end{tabular}

La tabla menciona los fármacos cuyo uso hospitalario se ha reportado con mayor frecuencia, los fármacos en investigación y los medicamentos en fase III de investigación.

Modificado de: Huang $\mathrm{C}$ et al. ${ }^{1}$

bóticos que pueden agravar el cuadro del paciente. Previo al inicio de este tratamiento se debe verificar la ausencia de contraindicaciones como puede ser sangrado activo o recuento de plaquetas menor de 25,000. Si la anticoagulación está contraindicada, los pacientes deben recibir profilaxis mecánica. ${ }^{11,20}$

Por último, se alienta a los lectores a mantenerse informados sobre futuras actualizaciones en el tratamiento, prevención de complicaciones y desarrollo de nuevos fármacos para pacientes con COVID-19. Recomendamos los siguientes sitios web: https://www.covid19-druginteractions. org/ y https://clinicaltrials.gov/ para más información sobre esta sección (Tabla 1).

\section{Estatus del desarrollo de una vacuna y el uso de plasma convaleciente para el tratamiento de pacientes positivos a COVID-19}

Hasta el momento no se ha desarrollado una vacuna eficiente ni un tratamiento específico contra el COVID-19. La vacuna es la forma más eficaz de controlar los brotes, por lo que la comunidad internacional ha intensificado los esfuerzos para desarrollar una contra la infección por SARSCoV-2. En general, se cree que las vacunas vivas atenuadas serán las más eficaces contra los coronavirus. ${ }^{9}$

En el Reino Unido, el Centro de Vacunología Clínica y Medicina Tropical del Hospital de Churchill se encuentra realizando un estudio utilizando una nueva vacuna llamada ChAdOx1 nCoV-19, con el objetivo de evaluar si tiene la capacidad de generar respuesta inmunitaria contra el virus en personas sanas, además de proporcionar información sobre la seguridad de la vacuna. En este estudio se están reclutando adultos sanos mayores de 18 años y niños de cinco a 12 años, la participación es voluntaria y los participantes se están asignando aleatoriamente para que reciban la vacuna en investigación. Asimismo, se les realiza estudios 
de sangre y se evalúa si presentan síntomas posteriores a la colocación de esta nueva vacuna. ${ }^{32}$

De igual manera, en China se está realizando un estudio doble ciego, controlado y comparado contra placebo, que actualmente se encuentra en fase I/II, el cual utiliza una vacuna con virus inactivado en población sana a partir de los tres años edad. Al igual que el estudio en el Reino Unido, el objetivo es evaluar la inocuidad e inmunogenicidad de la vacuna. ${ }^{33}$ Actualmente, existen otros protocolos de investigación que del mismo modo se encuentran en el desarrollo de una vacuna contra el COVID-19. Sin embargo, aún no están reclutando personas para continuar con las investigaciones.

Por otro lado, en Irán se realizan pruebas utilizando plasma de individuos convalecientes para tratar pacientes que presentan neumonía severa en la unidad de terapia intensiva debido a la infección por SARS-CoV-2. ${ }^{34}$ Esta alternativa de tratamiento se ha descrito en diversos artículos, los cuales utilizan plasma de individuos que se han recuperado de COVID-19 que tienen resultado negativo a la prueba de RT-PCR para COVID-19 e IgM, para SARS-CoV-2, pero resultado positivo para IgG. Se administra de 200-300 mL de plasma en pacientes con cuadro clínico crítico en la unidad de terapia intensiva, principalmente pacientes con neumonía severa y entre 61 y 73 años de edad..$^{35}$ Se ha demostrado que el uso de plasma convaleciente puede ayudar a detener la diseminación del virus y extender la supervivencia en pacientes con COVID-19 e insuficiencia respiratoria. Sin embargo, no puede reducir la tasa de mortalidad en pacientes críticos con enfermedad terminal. ${ }^{35-37}$

Asimismo, se ha reportado que la viremia alcanza su punto máximo en la primera semana de la infección, los pacientes generalmente desarrollan una respuesta inmunológica primaria entre 10 y 14 días, seguida de la eliminación del virus. Durante la tercera, se considera que el deterioro clínico y el daño tisular es el resultado del proceso inflamatorio y/o hiperinmune causado por la infección. Por lo que el uso del plasma convaleciente debería ser más efectivo durante la etapa temprana de la enfermedad, es decir, antes del día 14 o durante la etapa virémica y seronegativa. ${ }^{35,38}$ Las principales reacciones adversas que se han detectado son eventos relacionados con la transfusión, lo cual incluye escalofríos, fiebre, reacciones anafilácticas, lesión pulmonar aguda relacionada con la transfusión, sobrecarga circulatoria y hemólisis. ${ }^{38}$

A pesar de que el uso de plasma convaleciente ha demostrado ligeras mejorías en el estado crítico de pacientes con COVID-19, se requiere mayor investigación y estudios que demuestren su verdadero beneficio en la infección por SARS-CoV-2 y los posibles efectos adversos a corto, mediano y largo plazo.

\section{Prevención, precauciones y cuidados personales para evitar infección por SARS-CoV-2}

Las mejores medidas para controlar los coronavirus humanos siguen siendo un fuerte sistema de vigilancia de salud pública junto con pruebas de diagnóstico rápido y cuarentena cuando sea necesario. En caso de brotes internacionales, como sucede actualmente con SARS-CoV-2, la cooperación de las entidades gubernamentales, las autoridades de salud pública y los proveedores de atención médica es fundamental. ${ }^{9}$

Las estrategias de prevención y control se deben realizar a nivel nacional, nivel de población relacionado con casos y nivel de población general. ${ }^{3}$ A nivel nacional, los institutos médicos pueden adoptar tratamientos de aislamiento y protocolos de observación para prevenir y controlar la propagación, además de pautas nacionales para prevenir la infección nosocomial de SARS-CoV-2, lo cual incluye el aislamiento de casos, la identificación y el seguimiento de los contactos, la desinfección ambiental y el uso de equipos de protección personal. ${ }^{3}$ Asimismo, la OMS recomienda el uso de mascarillas N95 o FFP2 para los trabajadores de la salud cuando realicen procedimientos de generación de aerosoles y el uso de máscaras médicas cuando prestan atención a casos sospechosos o confirmados.,18

Para la población general no existe por el momento una vacuna que prevenga SARS-CoV-2, por lo que la mejor prevención es evitar exponerse al virus. ${ }^{3}$ Las medidas de

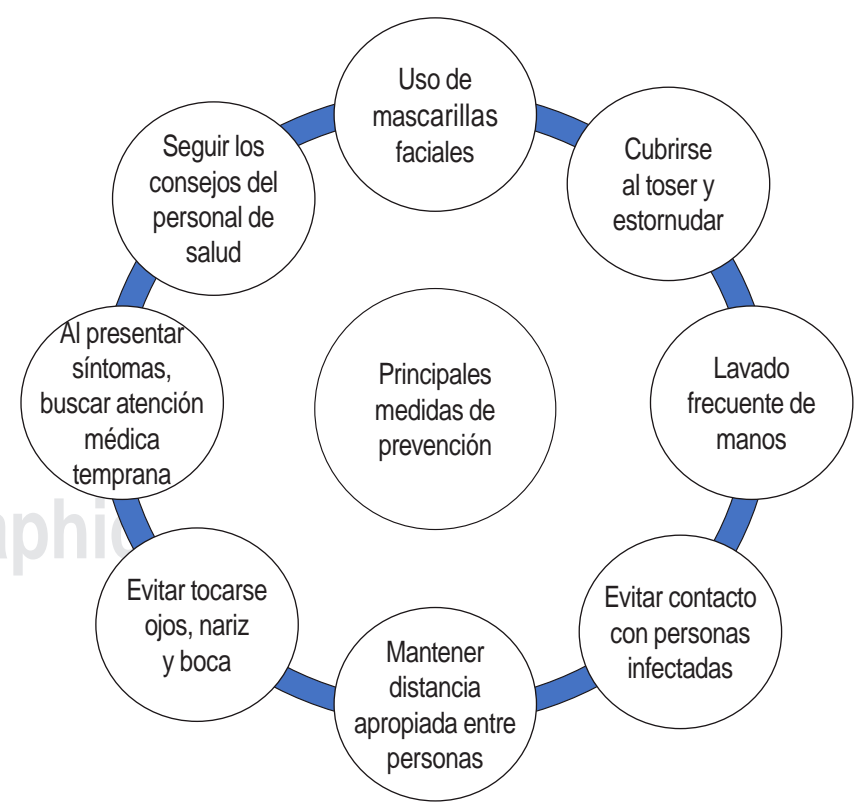

Figura 3: Principales medidas de prevención para el COVID-19. Esta imagen menciona las principales medidas de prevención que se han implementado a nivel mundial para evitar la infección por el nuevo coronavirus. Modificado de: Fu B et al. ${ }^{17}$ 
prevención y control de infecciones que pueden reducir el riesgo de exposición incluye el uso de mascarillas faciales, cubrirse la boca con el codo flexionado al toser o estornudar; lavado regular de manos con jabón o gel desinfectante, el cual debe contener al menos $60 \%$ de alcohol; evitar el contacto con personas infectadas y mantener una distancia adecuada, al menos $1 \mathrm{~m}$ (3 pies) de distancia entre usted y cualquier persona que esté tosiendo o estornudando; abstenerse de tocarse los ojos, la nariz, la boca con las manos sin lavar y seguir los consejos de los proveedores de salud (Figura 3).3,18,19

Además, la OMS recomienda que las personas con síntomas respiratorios usen máscaras médicas en el hogar, $^{7}$ al igual que la adecuada eliminación de las mismas es importante para evitar cualquier riesgo de transmisión. ${ }^{7}$

\section{Reinfección en pacientes previamente infectados por SARS-CoV-2}

En los últimos días se ha esparcido la noticia de una posible reinfección en pacientes previamente infectados por el virus SARS-CoV-2. Sin embargo, actualmente se conoce que hay posibilidades de $0 \%$ de reinfección en pacientes recuperados por COVID-19 cuando hay interacción por contacto con población susceptible. Por lo tanto, a medida que la tasa de recuperación continúa creciendo de manera constante, el número de pacientes recuperados que han sido clínicamente declarados libres del virus por la prueba de PCR también se declaran no infecciosos, siempre que el virus se elimine por completo de su sistema. ${ }^{15} \mathrm{~A}$ su vez, se ha reportado una alta tasa de falsos negativos en los resultados de COVID-19 mediante el uso de RT-PCR, que es el método diagnóstico de elección. ${ }^{14}$

Por otro lado, Xiao et al. mencionan que los pacientes en fase de recuperación «se vuelven positivos». Después de realizar un estudio con 70 pacientes positivos a SARSCoV-2 se demostró que 21.4\%, 15 pacientes reportaron el «giro positivo» utilizando la prueba de RT-PCR después de dos pruebas negativas consecutivas. Se reportó que este giro sucede en un período de 28-40 días, con una media de 36 días. Por lo que los pacientes pueden experimentar un falso negativo o aclaramiento viral prolongado, en vez de una reinfección por este virus. ${ }^{39}$

De igual manera, se ha reportado que la tasa de conversión negativa comienza desde el sexto de día de hospitalización y sigue aumentado hasta el día $15 .{ }^{40}$ Mientras que otros estudios mencionan que la mediana de tiempo desde el inicio de los síntomas hasta los primeros resultados negativos por RT-PCR en muestras de hisopos orofaríngeos es de 9.5 días. Además, se ha identificado que los pacientes infectados por SARS-CoV-2 presentan resultado positivo después del tiempo promedio de aclaramiento viral en muestras de heces..$^{40,41}$

\section{CONCLUSIONES}

Después de recolectar, analizar y comparar la información más relevante sobre COVID-19 podemos concluir que, a pesar de todas las investigaciones y datos que se han reportado, aún es necesario seguir estudiando el mecanismo de infección, manifestaciones clínicas, complicaciones y futuras secuelas secundarias a la infección por SARS-CoV-2. En los próximos meses se espera el desarrollo de una vacuna preventiva y de fármacos que inhiban la infección o disminuyan las complicaciones causadas por la historia natural de la enfermedad COVID-19.

\section{REFERENCIAS}

1. Huang C, Wang Y, Li X, Ren L, Zhao J, Hu Y, et al. Clinical features of patients infected with 2019 novel coronavirus in Wuhan, China. Lancet. 2020;395(10223):597-506. Available in: https://doi. org/10.1016/S0140-6736(20)30183-5

2. Fehr AR, Perlman S. Coronavirus: an overview of their replication and pathogenesis. Methods Mol Biol. 2015;1282:1-23. Available in: https://doi.org/10.1007/978-1-4939-2438-7_1

3. Adhikari SP, Meng S, Wu YJ, Mao YP, Ye RX, Wang Q-Z, et al. Epidemiology, causes, clinical manifestation and diagnosis, prevention and control of coronavirus disease (COVID-19) during the early outbreak period: a scoping review. Infect Dis Poverty. 2020;9(1):29. Available in: https://doi.org/10.1186/s40249-02000646-x

4. Zhu N, Zhang D, Wang W, Li X, Yang B, Song J, et al.; China Novel Coronavirus Investigating and Research Team. A novel coronavirus from patients with pneumonia in China, 2019. N Engl J Med. 2020;382(8):727-733. Available in: https://doi.org/10.1056/ nejmoa2001017

5. Solís A. Confirman primer positivo de coronavirus Covid-19 en México. Forbes Staff [en línea]. 28 febrero 2020. [Fecha de consulta 30 de mayo de 2020] Accesible en: https://www.forbes.com.mx/confirmanel-primer-caso-de-coronavirus-covid-19-en-mexico/

6. Gobierno de la Ciudad de México. Situación actual Covid-19 CDMX (2020) [en línea]. [Fecha de consulta 30 de mayo de 2020] Accesible en: https://datos.cdmx.gob.mx/pages/covid19/?gclid=CjwKCAjwiMj2 BRBFEiwAYfTbCpGrk95qVjrlIZffykcTU-jJYcKJarwfG2jjUTGeWtz|Qo fxnv3ahxoCheQQAvD_BwE

7. World Health Organization. Coronavirus (COVID-19) events as they happen [Internet]. [Access date 2020 April 28] Available from: https:// www.who.int/emergencies/diseases/novel-coronavirus-2019/eventsas-they-happen

8. Perlman S. Anorher decade, another coronavirus. N Engl J Med. 2020;382(8):760-762. Available in: https://doi.org/10.1056/ nejme2001126

9. Chen ZM, Fu JF, Shu Q, Chen YH, Hua CZ, Li FB, et al. Diagnosis and treatment recommendations for pediatric respiratory infection caused by the 2019 novel coronavirus. World J Pediatr. 2020;16(3):240-246. Available in: https://doi.org/10.1007/s12519-020-00345-5

10. Guo YR, Cao QD, Hong ZS, Tan YY, Chen SD, Jin HJ, et al. The origin, transmission and clinical therapies on coronavirus disease 2019 (COVID-19) outbreak - an update on the status. Mil Med Res. 2020;13(1):11. Available in: https://doi.org/10.1186/s40779-020-00240-0 
11. Guana ME, Bernava JL. Recomendaciones diagnósticas y terapéuticas ante la respuesta inmune trombótica asociada a Covid-19 [en línea]. [Fecha de consulta 1 de mayo de 2020] Accesible en: https://fundacionio.com/wp-content/uploads/2020/04/ Si\%CC\%81ndrome-RITAC.pdf.pdf.pdf.pdf.pdf.pdf.pdf

12. Tian $Y$, Rong L, Nian W, He Y. Review article: gastrointestinal features in COVID- 19 and the possibility of fecal transmission. Aliment Pharmacol Ther. 2020;51(9):843-851. Available in: https:// doi.org/10.1111/apt.15731

13. Van Doremalen N, Bushmaker T, Morris DH, Holbrook MG, Gamble A, Williamson BN, et al. Aerosol and surface stability of SARS- CoV-2 as compared with SARS-CoV-1. N Engl J Med. 2020;382(16):1564-1567. Available in: https://doi.org/10.1056/ nejmc2004973

14. Okhuese AV. Estimation of the probability of reinfection with COVID-19 by the susceptible-exposed-infectious-removed-undetectablesusceptible model. JMIR Public Health Surveill. 2020;6(2):e19097. Available in: https://doi.org/10.2196/19097

15. Lee $Y$, Min P, Lee S, Kim SW. Prevalence and duration of acute loss of smell or taste in COVID-19 patients. J Korean Med Sci. 2020;35(18):e174. Available in: https://doi.org/10.3346/ jkms.2020.35.e174

16. Pérez-Suárez B, Martínez-Menchon T, Cutillas-Marco E. Hallazgos cutáneos en la pandemia de COVID-19 en la Región de Murcia (carta al editor). Med Clin (Barc). 2020;155(1):41-42. Disponible en: https:// doi.org/10.1016/j.medcli.2020.05.001

17. Fu B, Fu X. Clinical characteristics of 11 asymptomatic patients with COVID-19. Med Clin (Barc). 2020;155(2):87-88. Available in: https:// doi.org/10.1016/j.medcli.2020.04.013

18. Rothan HA, Byrareddy SN. The epidemiology and pathogenesis of coronavirus disease (COVID-19) outbreak. J Autoimmun. 2020;109:102433. Available in: https://doi.org/10.1016/j. jaut.2020.102433

19. Gennaro FD, Pizzol D, Marotta C, Antunes M, Racalbuto V, Veronese $\mathrm{N}$, et al. Coronavirus diseases (COVID-19) current status and future perspectives: a narrative review. Int J Environ Res Public Health. 2020;17(8):2690. Available in: https://doi.org/10.3390/ ijerph17082690

20. Massachusetts General Hospital. 2020 [en línea]. [Fecha de consulta 1 de mayo de 2020]. Accesible en: https://www.massgeneral.org/ assets/MGH/pdf/news/coronavirus/aspectos-hematol\%C3\%B3gicosdurante-el-COVID-19.pdf

21. Bhimraj A, Morgan RL, Shumaker AH, Lavergne V, Baden L, Cheng Vincent CC, et al. Infectious Diseases Society of America Guidelines on the Treatment and Management of Patients with Coronavirus 2019 (COVID-19). Clin Infect Dis. 2020: ciaa478. Available in: https://doi. org/10.1093/cid/ciaa478

22. Treatments for COVID-19: Canadian Arm of the SOLIDARITY Trial (CATCO). 2020 [online]. [Access date 2020 09 Jun 09] Available from: https://clinicaltrials.gov/ct2/show/NCT04330690?term=Remdesivir\& recrs $=$ ade\&cond $=$ COVID\&draw $=2 \&$ rank $=6$

23. The Efficacy of Different Anti-viral Drugs in COVID 19 Infected Patients. 2020 [online]. [Access date 2020 Jun 09] Available from: https://clinicaltrials.gov/ct2/show/NCT04321616?term=Remdesivir\& recrs=ade\&cond=COVID\&draw $=2 \&$ rank $=7$

24. Shang L, Zhao J, Hu Y, Du R, Cao B. On the use of corticosteroids for 2019-nCoV pneumonia. Lancet. 2020;395(10225):683-684. Available in: https://doi.org/10.1016/s0140-6736(20)30361-5
25. Corticosteroids during Covid-19 Viral pneumonia related to SARSCoV-2 infection (CORTI-Covid). 2020 [online]. [Access date 2020 Jun 10] Available from: https://clinicaltrials.gov/ct2/show/NCT04344288? term $=$ corticosteroids \&cond=COVID-19\&draw $=2 \&$ rank $=2$

26. Early Short Cpurse Corticosteroids in COVID-19. 2020 [online]. [Access date 2020 Jun 10] Available from: https://clinicaltrials.gov/ ct2/show/study/NCT04374071?term=corticosteroids\&cond=COV ID-19\&draw=2\&rank=8

27. Efficacy and Safety of Corticosteroids in COVID-19. 2020 [online]. [Access date 2020 Jun 10] Available from: https://clinicaltrials.gov/ ct2/show/NCT04273321?term=corticosteroids \&cond=COVID19\&draw $=2 \&$ rank $=6$

28. Assessment of Efficacy and Safety of Ruxolitinib in Participants With COVID-19-Associated ARDS Who Require Mechanical Ventilation (RUXCOVID-DEVENT) [online]. [Access date 2020 Jun 09] Available from: https://clinicaltrials.gov/ct2/show/NCT04377620?term=Ruxoliti nib\&recrs=ade\&cond=COVID\&draw $=2 \&$ rank $=1$

29. Phase 3 Randomized, Doble-blind, Placebo-controlled Multi-center Study to Assess the Efficacy and Safety of Ruxolitinib in Patients With COVID-19 Assiciated Cytokine Storm (RUXCOVID)(RUXCOVID) [online]. [Access date 2020 Jun 09] Available from: https://clinicaltrials. gov/ct2/show/NCT04362137?term=Ruxolitinib\&recrs=ade\&cond=CO VID\&draw $=2 \&$ rank $=2$

30. Treatment of SARS Caused by COVID-19 With Ruxolitinib [online]. [Access date 2020 Jun 09] Available from: https://clinicaltrials.gov/ ct2/show/NCT04334044?term=Ruxolitinib\&recrs=ade\&cond=COVI $D \& d r a w=2 \& r a n k=3$

31. Study of Ruxolitinib Plus Simvastatina in the Prevention and Treatment of Respiratory Failure of COVID-19. (Ruxo-Sim-20) [online]. [Access date 2020 Jun 09] Available from: https://clinicaltrials.gov/ct2/show/ NCT04348695?term =Ruxolitinib\&recrs=ade\&cond=COVID\&draw $=$ 2\&rank $=6$

32. Plested E. Investigating a vaccine against COVID-19. 2020. Available in: https://doi.org/10.1186/ISRCTN90906759

33. A phase I/II clinical trial for inactivated novel coronavirus (2019CoV) vaccine (Vero cells). Chictr.org.cn. 2020 [online]. [Access date 2020 May 31] Available from: http://www.chictr.org.cn/showproj. aspx?proj $=53003$

34. Use of convalescent plasma in the treatment of patients with severe COVID-19 pneumonia. En.irct.ir. 2020 [online]. [Access date 2020 May 31] Available from: https://en.irct.ir/trial/47266

35. Zeng QL, Yu ZJ, Gou JJ, Li GM, Ma SH, Zhang G, et al. Effect of convalescent plasma therapy on viral shedding and survival in patients with coronavirus disease 2019. J Infect Dis. 2020;222(1):38-43. Available in: https://doi.org/10.1093/infdis/jiaa228

36. Roback JD, Guarner J. Convalescent plasma to treat COVID-19: possibilities and challenges. JAMA. 2020;323(16):1561-1562. Available in: https://doi.org/10.1001/jama.2020.4940

37. Syal K. COVID-19: Herd immunity and convalescent plasma transfer therapy. J Med Virol. 2020. Available in: https://doi.org/10.1002/ imv. 25870

38. Zhao Q, He Y. Challenges of convalescent plasma therapy on COVID-19. J Clin Virol. 2020;127:104358. Available in: https://doi. org/10.1016/j.jcv.2020.104358

39. Xiao AT, Tong YX, Zhang S. False-negative of RT-PCR and prolonged nucleic acid conversion in COVID-19: Rather than recurrence [published online ahead of print, 2020 Apr 9]. J Med Virol. 2020;10.1002/jmv.25855. Available in: https://doi.org/10.1002/jmv.25855 
40. Yuan J, Zou R, Zeng L, Kou S, Lan J, Li X, et al. The correlation between viral clearance and biochemical outcomes of 94 COVID-19 infected discharged patients. Inflamm Res. 2020;69(6):599-606. Available in: https://doi.org/10.1007/s00011-020-01342-0

41. Ling Y, Xu SB, Lin YX, Tian D, Zhu ZQ, Dai FH, et al. Persistence and clearance of viral RNA in 2019 novel coronavirus disease rehabilitation patients. Chin Med J (Engl). 2020;133(9):1039-1043. Available in: https://doi.org/10.1097/cm9.0000000000000774

Financiamiento: El presente artículo de revisión no ha recibido ninguna beca, financiamiento ni donación de agencias del sector público, comercial o privado.
Responsabilidades éticas: Protección de personas y animales: Los autores declaran que para esta investigación no se han realizado experimentos en seres humanos ni animales.

Confidencialidad de los datos: Los autores declaran que han seguido los protocolos de su centro de trabajo sobre la publicación de datos de pacientes.

Derecho de la privacidad y consentimiento informado: Los autores declaran que en este artículo no aparecen datos personales de pacientes.

Conflicto de intereses: Los autores declaran no tener conflicto de intereses. 